\title{
MEMÓRIAS DE VIAJANTES: PAISAGENS E LUGARES DE UM NOVO MUNDO
}

\author{
WERTHER HOLZER* \\ Universidade Federal Fluminense
}

Qualquer trabalho que se refira à espacialidade humana deve referir-se à memória. Como diz Lowenthal:

O passado nos rodeia e nos satura; toda cena, todo enunciado, toda ação conserva conteúdo residual dos tempos passados. ... Séculos de tradição suportam cada instante de percepção e de criação, permeiam não somente os artefatos e a cultura mas as células de nossos corpos. (LOWENTHAL, 1985, grifo meu).

Se considerarmos que os indivíduos e as culturas apropriam-se dos espaços naturais, constituindo-os em artefatos a partir de suas intenções e de suas ações, a memória e a transmissão parcial das experiências prévias torna-se fundamental para a compreensão dessas ações.

A preocupação deste trabalho é de como a memória contribui para a constituição de categorias espaciais. Como aparece intermediando o espaço objetivo, que se dá aos sentidos, e o espaço subjetivo, que é produzido e processado a partir das experiências imediatas e das experiências prévias.

\footnotetext{
* Arquiteto e Urbanista, Doutor em Geografia Humana, Professor da Graduação em Arquitetura da Universidade Federal Fluminense. Este Artigo, em outra versão, foi apresentado no II Encontro Interdisciplinar sobre o Estudo da Paisagem, realizado em Bauru - SP, em 1996, e resume alguns dos temas de Tese defendida na USP em 1998.
} 
Neste sentido, se retornarmos a Lowenthal, a

memória e a história são processos de introspeção (insight); ... a memória é inescusável e, à primeira vista, indubitável; a história é contingente e pode ser empiricamente testada. Diversamente da memória e da história, as relíquias não são processos, mas resíduos de processos. As relíquias produzidas pelo homem se chamam artefatos; aquelas que são naturais não possuem um nome específico. (LOWENTHAL, 1985).

Que momento poderia ser mais propício para uma discussão acerca da memória, das relíquias e da espacialidade que o das primeiras visitas européias à América?

Trata-se da descoberta de um Novo Mundo, intocado e desconhecido do europeu. Ele iria ser apropriado e assimilado (constituindo-se em paisagens), resultando na transmissão de experiências e na exigência de ações (que constituem os lugares).

Para efeito da empiria e da história o objeto deste estudo foi geograficamente e historicamente situado. O local quis que fosse próximo, conhecido, para que pudesse confrontar o momento da descoberta com sua situação atual. Este é um dos modos possíveis de aproximar as memórias remotas com nossas experiências e memórias contemporâneas. Foi, pois, delimitado um trecho litorâneo do Brasil Meridional.

O momento escolhido foi o dos primeiros relatos espontâneos de contato com o Brasil: momento das primeiras incursões européias, em 1550. A escolha recaiu sobre dois viajantes que estiveram na faixa litorânea delimitada: Hans Staden (1995) e Jean de Léry (1980).

\section{A geografia humanista: memória, história, espacialidade}

Uma aproximação entre memória, história e espacialidade pode ser feita a partir da geografia humanista e, em particular, a partir da obra de Lowenthal. O autor, um dos primeiros humanistas, tem também ligações profundas com a geografia cultural e com a geografia histórica. Suas preocupações com uma nova epistemologia da geografia provêm de sua formação, e seriam enunciadas em 1961.

Estas idéias estão contidas em um artigo (LOWENTHAL, 1961), em que eram retomadas propostas de John Wright (1947) que sugeria o fim da delimitação entre objetividade e subjetividade na geografia. O caminho proposto era o do estudo da imaginação geográfica e de sua diferenciação das imagens mentais, que podiam ser meramente invocadas pela memória.

A argumentação a respeito da subjetividade conduz à questão central proposta por Wright: a de que os geógrafos não devem se ater à sua imaginação geográfica, considerando também a dos outros. Segundo este ponto de vista, a geografia era composta por dois domínios: o que envolve os estudos formais, o que inclui estudos não cientí- 
ficos (relatos de viagem, ficção, pintura) e concepções geográficas subjetivas de pessoas comuns.

Lowenthal, ao retomar estas questões, considerava que a geografia é a ciência que mais se aproxima da vida quotidiana, pois "O universo do discurso se centraliza no conhecimento e idéias sobre o homem e o meio; qualquer um que examine o mundo em torno de si, de algum modo será um geógrafo." (LOWENTHAL, 1961).

Isso não significa que todos compartilham da mesma visão de mundo. Elas se referem a diferentes fatores e mudam a cada geração, apesar da capacidade do passado em retardar uma mudança no consenso geral. Além disso, somente uma parte destas visões é incorporada à imagem geral.

Existiria uma dialética entre a visão geral e a visão pessoal de mundo. Esta dualidade nos remete a uma constante na obra de Lowenthal: a do papel do passado como determinante de nossa visão de mundo. Para o autor "O conhecimento pessoal, assim como o geográfico, é uma forma de ocupação seqüencial. Assim como a paisagem ou um ser vivo, cada mundo pessoal teve um curso no tempo, uma história própria." (LOWENTHAL, 1961).

\section{Paisagem e lugar como receptáculo de memória}

Neste trabalho utilizarei as definições sugeridas pela geografia cultural e pela geografia humanista para a paisagem e o lugar.

O lugar nunca se destacou como conceito da geografia, sendo quase sempre tomado como referência locacional. Já a paisagem é um tema central, sendo definida inicialmente como um ambiente físico uniforme que propicia a ocupação humana homogênea. Definições que seriam revistas pela geografia cultural e pela geografia humanista.

O conceito de lugar ganhou importância na geografia após a adoção do aporte proveniente da fenomenologia existencialista. Já em 1952, Dardel (1990) propunha que o pólo de tensão na relação do homem com a Terra estaria no conceito de "distância". Ela obrigaria a constituição do mundo a partir das referências corporais. A direção, adicionada à distância, resultaria em um sítio estável: o lugar de nossa existência.

Tuan $(1974,1977)$ retomaria a questão. Segundo ele, o lugar encarna as experiências e as aspirações pessoais, é uma realidade que deve ser compreendida da perspectiva dos que lhe dão significado.

O lugar é definido como um conjunto complexo, enraizado no passado e incrementando-se com a passagem do tempo, com o acúmulo de experiências e de sentimentos. Seria a experiência primitiva do espaço experimentada a partir do corpo.

Tempo e espaço relacionam-se com a distância: são estruturados e orientados pela intencionalidade humana. O tempo, inseparável da atividade locomotora, está implícito nos lugares, a partir das idéias de movimento, esforço, liberdade, objetivo e acessibilidade. 
Lugar e tempo relacionam-se de três modos: tempo como movimento ou fluxo; lugar como pausa na corrente temporal, afeição pelo lugar em função do tempo; lugar como tempo visível ou lembrança de tempos passados.

Neste texto, lugar será conceituado como um mundo de significados organizados em torno das noções de corpo, distância, direção, de um receptáculo de memória.

No que se refere à paisagem, pode-se iniciar pela definição de Sauer (1983) para a "paisagem cultural". O autor compreendia a paisagem como o processo físico e cultural de formatação da Terra. Formatação gerada pelo "fatos do lugar", e pela análise da constituição, limites e relações genéricas entre paisagens.

Sauer (1983) define a paisagem como um conceito maior que o todo visível de seus constituintes. Suas qualidades físicas seriam determinadas a partir de suas características de habitat presente ou potencial. Deste modo, a cultura seria o agente, a área natural o meio, a paisagem o resultado.

A definição de paisagem que considero apropriada é a seguinte:

A paisagem é uma marca, porque ela exprime uma civilização; mas também é uma matriz, porque participa de esquemas de percepção, de concepção e de ação, isso é, da cultura, que canalizam, em certo sentido, a relação de uma sociedade com o espaço e com a natureza, em outras palavras, com a paisagem de seu ecúmeno." (BERQUE, 1984).

Seja como marca, seja como matriz, a paisagem é uma expressão física da ação do homem sobre a natureza, e por extensão, um receptáculo de memória.

\section{Recordações de terras distantes}

Quatrocentos e cinqüenta anos nos separam da experiência de vida de Staden e Léry. O que seria de nossa história sem a memória de seus relatos? Poucos vestígios desta época são visíveis - a memória de um espaço natural há muito modificado e de nações que já não existem. Os vestígios estão ocultos, nos genes das pessoas, dos animais e das plantas, no relevo, nos naufrágios e, principalmente, nos livros.

Podemos recorrer diretamente à memória dos que aqui estiveram, e nos relataram as suas experiências; ou à história, que segundo Duby (1989), é uma representação do passado que expressa as preocupações da época em que é construída.

Luís Costa Lima oferece subsídios para este trabalho ao considerar a descoberta do Novo Mundo e do Oriente como a responsável pelo transtorno na ordem discursiva vigente então na Europa. $\mathrm{O}$ transtorno seria causado pela “...emergência do sujeito individual enquanto instância fundamental no processo de conhecimento e na propagação da imprensa." (LIMA, s.d.). 
Outra observação do autor é de como o aparecimento da imprensa afetou a noção de corpo, excluindo a corporalidade do circuito da comunicação e ressaltando a intencionalidade da consciência de quem escrevia.

O aparecimento do indivíduo propiciou também o surgimento do conceito de paisagem na cultura ocidental. O transtorno na ordem discursiva, neste caso referente à pintura e à descoberta da perspectiva geométrica, não admitia mais múltiplos focos da cena, mas só o ponto de vista do observador que constitui a paisagem.

Este indivíduo é um ser novo, em construção. Sua narrativa não está mais no plano do divino e do preestabelecido. Está, como nos indica Lima, na descoberta do outro, na domesticação das diferenças (se é que elas são domesticáveis), na constatação de que real e ficcional, objetivo e subjetivo, são valores relativos.

Naquele momento, aventureiros de todas as classes sociais traduzem o mundo do outro para as convenções do seu próprio mundo. Eles são autores de uma obra pessoal, dotada de forte conotação memorialística.

A memória trabalhada aqui é aquela que Le Goff (1984) define como um comportamento narrativo que tem a função social de comunicar a outrem informações na ausência do fato que constitui seu motivo. E aquele é o momento em que se desequilibra a correlação entre memória falada e memória escrita. Nossos viajantes são os arautos da hegemonia da memória escrita.

Neste trabalho procuro, como sugere Duby (1989), selecionar vestígios segundo minhas preferências e meus interesses. Procurar os atos cotidianos ocultos sob a camada do excepcional - a captura de Staden, a traição sofrida por Léry -, que são os móveis da ação e que culminam com o registro e publicação de suas memórias individuais.

Minha metodologia, calcada nas proposições da geografia humanista, assemelha-se à de Rossi (1991), que sugere que a ambigüidade das idéias, das metáforas, dos modos de perceber e de pensar o mundo, do conhecimento não expresso, do estilo de pensamento, são elementos comuns de práticas que se propõem a explorar as múltiplas possibilidades de aproximação, e que encaram a história como objeto problemático e flutuante no tempo.

Deve se ter consciência de que se lidará muito mais com o que foi esquecido - com uma espacialidade obsoleta aos novos propósitos, em um ambiente modificado sob os nossos desígnios - do que com o que pode ser recortado, ou com o que é memorável.

Por outro lado, como nos lembra Lowenthal (1985), a memória é matéria-prima, é inescusável. Ela se refere ao processo, e os resíduos dos processos estão aí, na forma de artefatos ou de ambiente natural, para serem revisitados, reaproveitados, reinterpretados.

Nora (1993) sugere que a memória é vida e está em permanente evolução, é o elo vivido no eterno presente. Mas, para nós, está dada nos livros e, muito mais sutilmente, no ambiente, obrigando-nos a reconstituir o que já não existe, de fazer a história das paisagens, de lugares, de terras distantes que só existem na memória de viajantes que há muito partiram. 


\section{Dois viajantes e suas memórias de um novo mundo}

Ao ler os relatos de viagem, as memórias de Staden e de Léry, transparece a diversidade nos modos narrativos: o primeiro, mais "jornalístico", o segundo, mais "etnográfico".

Esta diversidade narrativa leva-me a especular sobre as motivações destes homens que se empenharam em empreitada tão difícil. As finalidades e as situações pelas quais passaram podem ter sido diversas, mas a motivação principal que os lançou ao mar e, mais tarde, os impulsionou a publicar as suas experiências, foram as mesmas: a curiosidade acerca de um mundo diferente do seu.

Parece proceder daí a preocupação de ambos os autores em cercar-se de cuidados que assegurem a veracidade de suas informações. A diversidade narrativa se deve, entre outros fatores, aos diferentes instrumentos utilizados para memorizar e transmitir as impressões da viagem. Será sobre este aspecto que me deterei agora.

Staden deixou sua terra natal com a intenção de aventurar-se pelas Índias. Não fosse por seu livro já teria há muito sido esquecido. Não temos notícias suas além das que ele fornece. Assim, sabemos que se empregou como artilheiro, donde se depreende que conhecia cartografia e cosmografia, corroboradas por suas informações exatas sobre distâncias e por seus esboços cartográficos.

Sua obra não transparece a intenção prévia do registro, o que seria de todo impossível depois de capturado pelos indígenas. O relato é feito de memória. Os nomes dos lugares e as distâncias, bem como suas feições são guardados "de cor".

Como nos sugere Le Goff (1984), sua narrativa é uma reconstrução generativa, que envolve uma memória técnica, ainda que rudimentar. Staden tem uma grande preocupação, que pode ser vital em uma fuga, na identificação dos lugares e no registro das ocorrências temporais. Pode-se dizer que o seu sistema mnemotécnico está voltado para o que Le Goff denomina de memória natural, ligada à oralidade, onde o sujeito se obriga a dispor em ordem lugares e imagens. No caso de Staden isso resulta na elaboração de mapas e de relatos bastante fiéis às regiões que visitou.

Para a memória natural, as relações espaciais e a espacialidade são fundamentais na construção do edifício da memória e do aparato mnemotécnico. O resultado do relato de Staden é de um texto telegráfico, "jornalístico", marcado pelas sequiências temporais e pelas seções espaciais que regem os passos do viajante.

Léry, que é um sacerdote em formação, parte para o Novo Mundo com a intenção de se fixar. Sua curiosidade está associada a sua missão religiosa e a um espírito metódico. O autor armazena informações sobre tudo o que vê, subsídios importantes para a instalação dos calvinistas na nova terra.

Frustrada a finalidade inicial, o autor confessa no prefácio que “... de volta à França não tinha eu a intenção de tornar públicas as memórias que escrevera, em grande parte com tinta do Brasil, e ainda na América, nem as coisas notáveis que observara, mas que de bom grado as contava pormenorizadamente aos que me inquiriam." (LÉRY, 1980). O autor só as publicaria anos mais tarde, sob instância de amigos, após recuperar por duas vezes os manuscritos perdidos. 
O distanciamento entre as experiências vividas e a publicação tornam-no mais rigoroso para com as fontes errôneas, levando-o a confrontar o material colhido em campo com o de outro viajante respeitável - Gomara, “... porque escreve várias coisas acerca dos índios do Peru, semelhantes às que referi dos selvagens da América." (LÉRY, 1980).

Existia também a preocupação de registrar o que era visto em desenhos, no que foi frustrado em diversas ocasiões, como no relato a seguir: "Por ser tão estranho em comparação com os animais da Europa, mais uma vez pedi a um tal de João Gardien, perito desenhista da nossa comitiva, que nos desenhasse, juntamente com os outros animais desconhecidos na Europa. Infelizmente ele nunca me atendeu." (LÉRY, 1980). Por outro lado não foram produzidos documentos cartográficos.

A preocupação de Léry em colocar no papel os acontecimentos da viagem, em ordená-los em forma de memória, leva-me a colocá-lo entre aqueles pioneiros do que Le Goff (1984) chama de revolução de memória pela imprensa. Daquele momento especial que pode ser identificado com o trecho seguinte de Leroy-Gourhan:

Até o aparecimento da imprensa ... dificilmente se distingue entre a transmissão oral e a transmissão escrita. A massa do conhecido está mergulhada nas práticas orais e nas técnicas; a área culminante do saber, com o quadro imutável desde a antigüidade, é fixada do manuscrito para ser apreendida de cor ... com o impresso ... não só o leitor é colocado na presença de uma memória coletiva enorme, cuja matéria não é mais capaz de fixar integralmente, mas que é freqüentemente colocado em situação de explorar textos novos. Assiste-se então à exteriorização progressiva da memória individual; é do exterior que se faz o trabalho de orientação que está escrito no escrito."

(Leroy-Gourhan, citado por LE GOFF, 1984).

O sistema de armazenamento da memória praticado por Léry já é moderno. Refere-se ao armazenamento de informações escritas e desenhadas desde a fonte. Seu sistema é o da memória artificial (LE GOFF, 1984). Seu estilo não segue necessariamente uma ordem espacial ou temporal, sendo que a primeira é particularmente inferiorizada. Neste caso, o relato visa a uma ordenação das anotações de campo. O resultado é um estilo "científico", "etnográfico", marcado por observações minuciosas acerca dos diferentes objetos de interesse do autor.

Pode se dizer que o transtorno na ordem discursiva imposto pela imprensa, como sugere Lima (s.d.), e pela descoberta do outro, como sugere Todorov (1993), vai aos poucos se impondo ao modo de pensar do europeu. Dai uma exigência cada vez maior de dados documentados que possam ser comparados com outros e confirmados em sua veracidade. Esvai-se a necessidade da presença imposta pela cultura oral.

No seu início a imprensa pouco se preocupa com a qualidade do informante. Os fatos são simplesmente aceitos como verídicos, produtos da memória de seus protagonistas, o que pode gerar problemas como os da demanda Thevet X Léry. 
Sob este aspecto as memórias de Staden se referem a uma postura medieval e se apoiam na tradição oral. Léry se enquadra em uma postura de vanguarda que, segundo Le Goff (1984), só iria consolidar-se no século XVIII com o alargamento da memória coletiva e com o enciclopedismo.

Léry está mais próximo de nós quando se trata de preocupações de estilo, mas seu suporte espaço-temporal é mais tênue e fragmentado. Os espaços vividos de Staden estão mais próximos de nós porque o suporte espacial compõe um todo, é uma das bases de seu sistema de memória.

\section{Os viajantes e os lugares}

Em outra parte deste artigo defini sucintamente o conceito de lugar. Vimos que suas variáveis implicam na orientação e estruturação do espaço a partir do corpo e da atividade locomotora.

Estas duas variáveis fundamentais só constituem o lugar quando originam um sítio estável. O lugar, portanto, implica em uma pausa no deslocamento, em um acúmulo de experiências e no aparecimento de expectativas e de aspirações em relação ao sítio, dando-lhe o significado especial de "lugar".

Segundo esta definição, a relação do viajante com o sítio é intermitente. O acúmulo de experiências ao longo do tempo é pequeno. Os viajantes que estudo aqui podem ser relacionados com os turistas do século XX: sua relação com o sítio é superficial, seus contatos com as pessoas são rápidos e descontínuos. Sua vida é um eterno movimento, sem pausa, sem estabilidade suficiente para o acúmulo de experiências relativas a um único sítio.

O livro de Staden é exemplar neste sentido. O autor narra em duas páginas a sua viagem de seis meses entre a Espanha e o Brasil. O roteiro é uma sucessão de distâncias, direções e pontos que foram tocados. Mesmo no litoral a base do viajante é o navio, as terras que desfilam aos seus olhos curiosos e só eles penetram nelas. O navio em deslocamento impede a constituição de um lugar.

Uma vez em terra o mesmo se repete. Ainda que baseado em um ponto, como no caso de Léry, há um deslocamento constante em busca de novidades e de descobertas. $\mathrm{O}$ autor, em um ano, visitou ao menos 13 aldeias na baía de Guanabara, algumas com frequiência, o que resulta em mais de um deslocamento por mês, e sabemos o quanto eram penosos nesta época.

Todorov observa bem isso a respeito de Colombo:

... ele parece encontrar na descoberta da natureza, atividade à qual se adapta melhor, um prazer que faz com que esta atividade se baste. Ela já não tem mínima utilidade, é um meio tornado fim. Assim como o homem moderno, uma coisa, uma ação ou um ser são belos apenas quando justificam-se a si mesmos. Para Colombo 'descobrir' é uma ação intransitiva. ... O que conta são as 'ter- 
ras', e a sua descoberta. Esta, na verdade, parece estar subordinada a um objetivo, que é o relato de viagem. (TODOROV, 1993).

Relph (1976) nos ensina que o lugar é o modo especial de se relacionar as diversas experiências de espaço. O lugar não pode ser experimentado como categoria definida, ou descrito em termos de localização ou aparência. Não pode ser confundido com a paisagem.

$\mathrm{Na}$ experiência do lugar existe a sensação de familiaridade, enquanto que na paisagem somos observadores, pessoas fora da cena. Por isso o papel do tempo, da vivência prolongada, é fundamental para a caracterização do lugar.

Relph observa ainda que os lugares devem sua identidade a três componentes interrelacionados: os traços físicos, as atividades e as funções observáveis. Nora (1993) fala, coincidentemente, em três sentidos para os lugares de memória, sentidos que funcionam simultaneamente: o material, o simbólico e o funcional. Também para esse autor a existência dos lugares de memória está condicionada a uma interrupção no fluxo do tempo.

Já disse que os lugares são receptáculos de memória. Sua constituição exige que todas as lacunas, todos os esquecimentos, sejam harmonizados pela rotina da vida quotidiana. Esta vivência e a experiência preenchem generosamente estas lacunas da memória, constituindo um ambiente integral que torna nossas ações mais seguras. Neste sentido, para os viajantes não existem lugares, não existe a segurança do conhecimento nem a certeza do tipo de decisão a ser tomada. Pode-se dizer que para os primeiros viajantes europeus não existe a memória dos lugares, a não ser a dos lugares dos outros. Assim, como veremos, eles só transmitiam a memória das paisagens.

\section{A paisagem dos viajantes}

Um dos impactos que tive ao ler Staden e Léry foi causado pela ausência quase total de descrições amplas do ambiente físico. As descrições são genéricas e fragmentadas. Como exemplo podemos citar:

Há uma grande serra, que se estende a 3 milhas do mar, ... e que chega mais ou menos até a altura da Boiga de Todoslos Sanctus. Esta serra se estende ao longo do mar por exatamente 204 milhas. ... Por detrás da serra há um planalto. Descem bonitos rios e nela há muita caça. (STADEN, 1955).

Acredito que a falta de preocupação com a descrição do ambiente físico se deva à existência da presença humana. O impacto do encontro com o outro, este é o assunto central de Staden e Léry.

O que interessa, então, é a paisagem. Ela já foi definida como o "processo físico de formatar a Terra." (SAUER, 1983). Mas a terra "descoberta" já estava formatada. Impunha-se para o europeu uma adaptação ou reformatação. 
A formatação, como nos aponta Sauer, implica na constituição e definição dos limites paisagísticos e na construção de relações genéricas com outras paisagens. Os europeus tomaram suas culturas e suas paisagens como referência para a formatação, impondo aos nativos o processo de adaptação.

Retomando a definição de Berque (1984) acerca da paisagem como marca e matriz, torna-se evidente que quando os europeus aportaram na América já existia uma marca sobre a matriz. Sou da opinião que os primeiros relatos descreviam principalmente estas marcas alheias, e apontavam para a constituição progressiva de uma nova matriz que se consolidaria no início do século XVIII. Durante séculos se perpetraria o genocídio dos nativos. Genocídio que, como todos, intenciona o desaparecimento da memória do outro para a construção de uma nova memória, ou, falando de paisagem, extinção de uma marca para a impressão de uma marca diversa.

A matriz de Staden e de Léry é uma mistura de elementos, que como aponta Lowenthal (1961), são marcados por imagens idealizadas e por preconceitos visuais. Temos um bom exemplo quando Léry narra suas expectativas negativas quando se preparava para a viagem:

E para que ninguém se iludisse acerca do longo e fastidioso trajeto que cumpria percorrer, ..., advertiu Du Pont que, em chegando a essa terra da América, seria necessário contentarem-se com uma certa farinha feita de raízes em lugar do pão; que não teriam vinho, nem notícias dele pois não havia aí parreiras $e$ finalmente no Novo Mundo far-se-ia mister levar uma vida em tudo e por tudo diferente da nossa Europa. (LÉRY, 1980).

Daí para a construção de arquétipos paisagísticos, segundo Tuan (1967), é um passo. Esses primeiros viajantes prepararam uma imagem, e uma memória coletiva do Mundo Tropical, que povoa nossa imaginação até hoje. Talvez seja o caso de procurarmos os nossos "lugares de memória" (NORA, 1993) no que os europeus pensam de nós.

Segundo essa visão arquetípica os índios são imprevisíveis e só pensam no canibalismo; animais e plantas são estranhos, deformados e ameaçadores. Do ambiente e do clima nem falar, o verde é perene, as tempestades constantes e imprevisíveis, existindo até chuvas fétidas e molestas (LÉRY, 1980).

Já disse que as paisagens, como os lugares, são receptáculos de memória. No entanto, por ser a paisagem expressão física da ação do homem sobre a natureza, ela retrata um instante. Ela expressa o que foi impresso e, neste sentido, o que passou torna-se menos legível. A matriz muitas vezes não é mais reconhecível. As marcas se misturam e as mais recentes predominam.

A paisagem é descontínua, marcada pelas lacunas da memória. Como nos sugere Rossi (1991), o esquecimento é um componente fundamental da memória. Neste caso, diversamente dos lugares, onde as lacunas compõe um ambiente integral, o esquecimento contribui para a fragmentação da paisagem, para a construção de arqué- 
tipos, onde as convenções constróem uma integridade sabidamente irreal. Staden e Léry nos ajudam a compreender como essas paisagens arquetípicas foram se constituindo ao longo do tempo.

\section{Conclusão}

Memória, paisagem e lugar. Espaço e tempo estão indissoluvelmente ligados. No estudo da espacialidade, não importa a que época se refira, a memória deve ser considerada. Quando tratamos do espaço tal qual ele era há 450 anos atrás, as toponímias, por exemplo, podem nos fornecer informações preciosas sobre as intenções e as ações do homem sobre o ambiente.

As toponímias podem nos informar sobre marcas difusas que nativos e europeus imprimiram na paisagem. Podem nos fornecer pistas sobre as matrizes originais. Elas nos falam, também, dos lugares e de seus atributos. As toponímias são a memória do que foi esquecido, e podem ser decodificadas.

Temos muito a extrair das memórias dos viajantes que aqui aportaram ao longo dos séculos. Sob este aspecto, as paisagens e os lugares não foram ainda devidamente analisados. Muitas possibilidades nos são oferecidas quando nos utilizamos da memória dos que aqui estiveram séculos atrás.

\section{MEMÓRIAS DE VIAJANTES: PAISAGENS E LUGARES DE UM NOVO MUNDO}

Resumo: O texto enfoca paisagem e lugar como receptores de memória, de como a memória contribui na constituição de categorias espaciais. A partir dos relatos de viagem de Jean de Lery e de Hans Staden, eu procuro mostrar a contribuição que a geografia humanista pode oferecer ao estudo dos lugares de memória, definidos como categorias espaciais referentes à memória.

Palavras-chave: Memória, lugar, paisagem.

\section{MEMORIES OF TRAVELLERS: LANDSCAPES AND PLACES OF A NEW WORLD}

Summary: The text focuses landscape and place as receivers of memory, as the memory contribute in the constitution of space categories. Starting from the reports of trip of Jean of Lery and Hans Staden, I try to show the contribution that the humanist geography can offer for the study from the places of memory, defined as space categories linked to the study of the memory.

Keywords: Memory, place, landscape.

\section{BIBLIOGRAFIA}

BERQUE, A (1984): Paysage-empreinte, paysage-matrice: eléments de problématique pour une géographie culturelle. L'Espace Géographique. 13 (4): 33-34.

DARDEL, E. (1990, 2a . ed.). L'Homme et la Terre - nature de la réalité géographique. Paris, Ed. CTHS. 
DUBY, G.; LARDREAU, G. (1989): Diálogos sobre a Nova História. Lisboa, Publicações Dom Quixote.

LE GOFF, J. (1984). Memória. in: Romano, R. (dir.). Enciclopédia Einaudi (Vol 1 Memória-História). Lisboa, Imprensa Nacional/Casa da Moeda, p. 11-50.

LÉRY, J. Viagem à terra do Brasil. Belo Horizonte/ São Paulo, Ed. Itatiaia/EDUSP.

LIMA, L.C. (s/d) O Transtorno da viagem. in: A Crônica: o gênero, sua fixação e suas transformações no Brasil. Campinas/Rio de Janeiro, Ed. UNICAMP/Fund. Casa de Rui Barbosa, p. 41-74.

LOWENTHAL, D. (1961): Geography, experience and imagination: towards a geographical epistemology. Annals of the Association of American Geographers. 51 (3): 241-260.

(1985): The past is a Foreign Country. Cambridge, Cambridge University Press.

LOWENTHAL, D.; PRINCE, H. (1964): English landscape tastes. Geographical Review. 59 (4): 530-556.

NORA, P. (1993): Entre memória e história: a problemática dos lugares. Projeto História. (10): 7-28.

SAUER, C. (1983). The morphology of landscape. In: Leighly (ed.). Land and life: a selection from the writtings of Carl Ortwin Sauer. Berkeley, University of California Press, p. 315-350.

RELPH, R. (1976): Place and Placelessness. Londres, Pion.

ROSSI, P. (1991): Il passato, la memoria, l'oblio: sei sagge di storia delle idde. Bolonha, Il Mulino.

STADEN, H. (1955): Viagem ao Brasil. Salvador, Livraria Progresso.

TODOROV, T. (1993): A conquista da América: a questão do outro. São Paulo, Martins Fontes, 1993.

TUAN, Y.F. (1967): Attitudes toward Environment: themes and approaches. in: Lowenthal, d. (ed.). Environmental perception and behavior. Chicago, The University of Chicago, p. 4-17.

(1974): Space and place: humanistic perspective. Progress in Human Geography. (6): 211-252.

(1977): Space and Place: the perspective of experience. Minneapolis, University of Minnesota Press.

WRIGHT, J. K. (1947): Terrae incognitae: the place of imagination in geography. Annals of the Association of American Geographers. 37 (1): 1-15. 